\title{
A Guidance chart for most probable solution directions in sustainable energy developments.
}

\begin{abstract}
his paper develops guidance framework for sustainable energy engineers. This guidance can be considered while looking towards some possible breakthrough solution for sustainable energy development. The research analyzes and refers core TRIZ based works related to sustainability, energy scenarios and eco-efficiency. It co-relates TRIZ philosophy, methods and tools in purview of energy and sustainability. It proposes guidelines in a tabular chart form which can help engineers as a framework in development of renewable and sustainable energy related future Progress. It provides most probable solution directions for forming the right conceptual solution before getting into detail design stages. Towards the end, it proposes a methodological flow chart for using the developed framework.
\end{abstract}

Keyword: Suntainable energy; Design guidance; TRIZ 